\title{
Metals and Metalloids Release from Orthodontic Elastomeric and Stainless Steel Ligatures: In Vitro Risk Assessment of Human Exposure
}

\author{
Aneta Olszewska ${ }^{1} \cdot$ Anetta Hanć $^{2} \cdot$ Danuta Barałkiewicz ${ }^{2} \cdot$ Piotr Rzymski $^{3}$ iD
}

Received: 21 August 2019 / Accepted: 14 October 2019 / Published online: 4 November 2019

(C) The Author(s) 2019

\begin{abstract}
Elastomeric ligatures are increasingly used as a part of esthetic orthodontic treatment, particularly in children. The aim of the present study was to experimentally test whether these appliances may contribute to exposure to toxic elements. In the present study, elastomeric ligatures (ELs) were incubated in artificial human saliva for 1 month (a typical period of their use) and the release of 21 metals (Ba, Cd, Co, Cr, Cu, Fe, Li, Mn, Mg, Mo, Ni, Pb, Rb, Tl, Ti, Sb, Sr, Sn, Zn, U, V) and 2 metalloids (As and $\mathrm{Ge}$ ) was studied using inductively coupled plasma-mass spectrometry. For comparison, stainless steel ligatures (SLs) were incubated for 1, 3, and 6 months (since sometimes their use is prolonged) under similar conditions. The determined metal levels were compared to the corresponding safety limits for human exposure. During 1 month, the ELs released Cd, Co, Cr, Mn, Ni, and Sn at total mean \pm SD level of $0.31 \pm 0.09,0.98 \pm 0.30,3.96 \pm 1.31,14.7 \pm 8.5,13.8 \pm 4.8$, and $49.5 \pm 27.7 \mu$ g, respectively. Other elements were always below the detection limits. In case of SL, the release of Co, Cr, Fe, Ni, Mn, and Sn was observed, and the determined values increased over the studied period. After 6 months, their total mean \pm SD levels amounted to $28.6 \pm 0.2,21.7 \pm$ $0.2,623.5 \pm 3.0,1152.7 \pm 1.8,5.5 \pm 0.3$, and $22.6 \pm 0.2 \mu \mathrm{g}$, respectively. The released metal levels from both ligature types were always below safety limits. The release of Ni from SL during 6 months would constitute 5.0 and $11.5 \%$ of tolerable intake in adults and children, respectively. The results of this in vitro study highlight that the use of ligatures in orthodontic treatment can be considered safe in terms of metal exposure although elastic ligatures replaced on a monthly basis appear to be advantageous in comparison to the prolonged use of stainless steel appliances.
\end{abstract}

Keywords Elastomeric ligatures $\cdot$ Metal exposure $\cdot$ Oral cavity $\cdot$ Artificial saliva $\cdot$ Nickel $\cdot$ Orthodontic appliances

\section{Introduction}

The release of trace elements from components installed internally for medical purposes may represent a relevant health threat. For example, elements released from some corrosionsusceptible orthopaedic implant alloys or hip and knee joint replacements can form complexes with proteins, activate the immune system, migrate to different organs, and cause systemic implications [1-4]. It is also well established that

Piotr Rzymski

rzymskipiotr@ump.edu.pl

1 Department of Facial Malformation, Poznan University of Medical Sciences, Poznań, Poland

2 Department of Trace Element Analysis by Spectrometry Method, Faculty of Chemistry, Adam Mickiewicz University, Poznań, Poland

3 Department of Environmental Medicine, Poznan University of Medical Sciences, Poznań, Poland amalgamate dental fillings can contribute to exposure to $\mathrm{Hg}$ [5], a phenomenon that has eventually led to a ban or a significant restriction on their use in developed countries but has also instilled a fear of poisoning in some dental patients [6]. The use of any orthodontic devices installed intraorally for a prolonged time must ensure that no significant release of toxic ions will occur. Such an assessment is particularly important because of their increased use as a result of improved dental awareness in the general population. The use of orthodontic brackets in particular has become common, and various systems are employed to ligate orthodontic arch wires including stainless steel ligatures and elastomeric ligatures [7].

Elastic ligatures are gaining increasing attention due to a number of advantages of their use: time-efficient, non-difficult application, reduced chair time, better patient comfort and satisfaction, and low cost [8-11]. Several companies manufacture different morphological models (ellipsoid, circular), varying in diameter and width, surface (rough or smooth), and color to meet the esthetical demand of patients and 
support their cooperation in the treatment process [12-14]. Elastomeric materials used in orthodontics are thermosetting polymers resulting from a step-reaction polymerization of polyesters or glycol polyesters and bi- or polyisothiocyanates $[15,16]$. They are easily pigmented, susceptible to rapid decay of force and deformation during the tensile load applied in the oral cavity, and must be changed periodically, every 3-4 weeks $[17,18]$. In turn, stainless steel ligatures are mostly used in the early stages of initial tooth alignment and leveling [19].

Orthodontic appliances and their components are exposed to a variety of intraoral conditions including those of saliva. Their degradation may potentially result in leaching of their components resulting in unintentional human exposure. It is therefore imperative to investigate whether these appliances may release potentially toxic elements during their use and constitute a relevant source of exposure in humans. Some previous studies have already evaluated the release of selected elements for various orthodontic appliances composed of alloys containing $\mathrm{Fe}, \mathrm{Cr}, \mathrm{Ni}, \mathrm{Si}$, and $\mathrm{Mo}$. The in vitro studies have consistently shown that in case of stainless steel appliances, the elements of concern include $\mathrm{Ni}$ and $\mathrm{Cr}$ [20-24]. This was further confirmed by in vivo observations, indicating that particularly $\mathrm{Ni}$ is released to a degree that its increase is detectable in human blood and urine [25-27]. Both, $\mathrm{Cr}$ and $\mathrm{Ni}$ have been recognized as cytotoxic, mutagenic, and allergenic $[28,29]$. At the same time, not much is known on the potential release of elements from elastic ligatures. However, some of these appliances, particularly ligatures composed of latex (which production may involve $\mathrm{Zn}$ compounds in the prevulcanization process) and made of polyurethane, were shown experimentally to display toxicity in vitro [30,31].

To fill this gap, the aim of the present study was to investigate the release of 21 metals $(\mathrm{Ba}, \mathrm{Cd}, \mathrm{Co}, \mathrm{Cr}, \mathrm{Cu}, \mathrm{Fe}, \mathrm{Li}, \mathrm{Mn}$, $\mathrm{Mg}, \mathrm{Mo}, \mathrm{Ni}, \mathrm{Pb}, \mathrm{Rb}, \mathrm{Tl}, \mathrm{Ti}, \mathrm{Sb}, \mathrm{Sr}, \mathrm{Sn}, \mathrm{Zn}, \mathrm{U}$, and $\mathrm{V}$ ) and 2 metalloids (As and $\mathrm{Ge}$ ) from elastomeric ligatures varying in color under in vitro conditions of artificial human saliva. Increased and long-term exposure to all of these elements may have an adverse health effects in human encompassing both systemic and organ-specific toxicity [32-34]. The selected ligatures varied in color as this has been previously shown as an important feature determining patients' preferences, e.g., girls were more likely to choose red and pink ligatures, boys preferred blue and green while adults preferred white and silver [35]. The release of elements from stainless steel ligatures was studied for comparison. Leaching of metals from fixed orthodontic appliances such as brackets or arch-wires has been studied both in vitro and in vivo [20-27] although it is unknown whether this process can also occur in the case of elastic ligatures and pose any relevant health risk. Therefore, the level of metal migration established experimentally in this research was also discussed with reference to maximum safe levels of exposure.

\section{Material and Methods}

\section{Ligatures}

Eleven commercially available latex-free elastomeric ligatures (Fig. 1) made of hypoallergenic medical grade thermoplastic polyurethane were purchased from American Orthodontics (USA), each in a different color: black, blue, burgundy, green, navy blue, orange pink, purple, red, yellow, and white. Stainless steel ligatures were purchased from Ormco (USA). The general composition of the alloy of the stainless steel ligatures was $17-20 \% \mathrm{Cr}, 8-12 \% \mathrm{Ni}, 0.15 \% \mathrm{C}$ balanced with $\mathrm{Fe}$. All ligatures had recent manufacturing dates at the time of experiment, were unused, and came in sealed plastic packages. The appliances employed in this study are globally distributed, including Europe.

\section{Experimental Design}

The superficial powder coating of the elastomeric ligatures was removed, and all elements were washed for $15 \mathrm{~s}$ with deionized water and dried with absorbent paper. Before testing, all ligatures were sterilized by exposure to ultraviolet light
Fig. 1 An example of elastic and stainless steel ligatures investigated in the present study

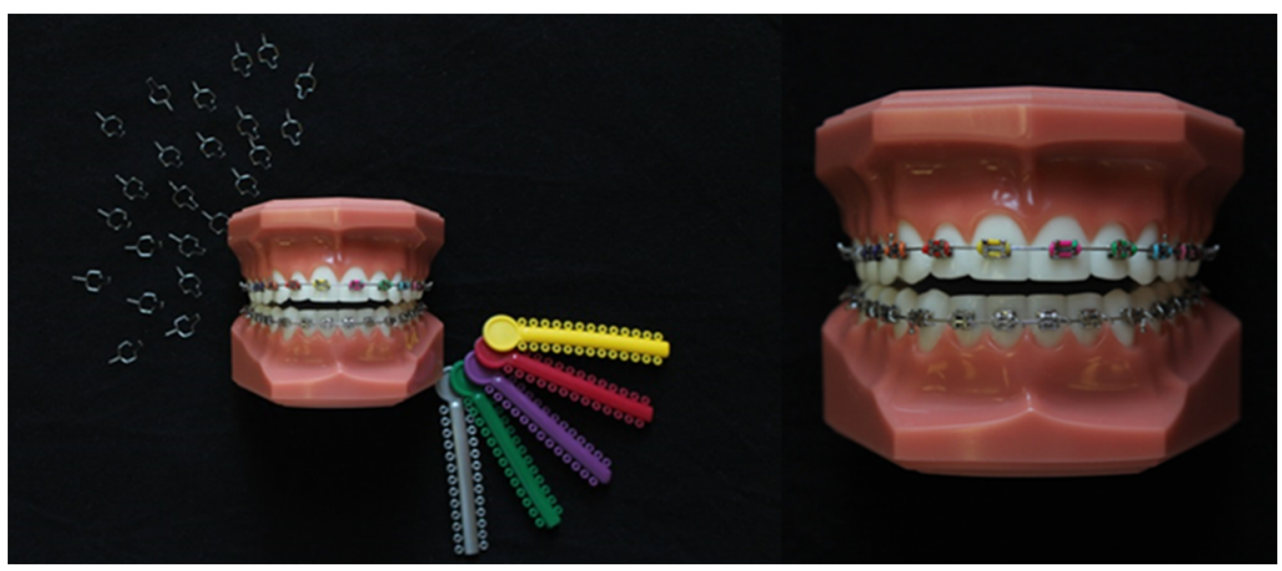


(Labconco, USA) for $30 \mathrm{~min}$. All ligatures were immersed in $30 \mathrm{~mL}$ of artificial saliva that contained $0.7 \mathrm{~g} \mathrm{NaCl}, 1.2 \mathrm{~g} \mathrm{KCl}$, $0.2 \mathrm{~g} \mathrm{KH}_{2} \mathrm{PO}_{4}, 1.5 \mathrm{~g} \mathrm{NaHCO}_{3}, 0.26 \mathrm{~g} \mathrm{Na}_{2} \mathrm{HPO}_{3}$, and $0.33 \mathrm{~g}$ KSCN (Sigma-Aldrich, USA). The elastomeric ligatures were incubated for 1 month (30 days) as this is the usual period of their use. Steel ligatures were incubated for 1 month (30 days), 3 months (90 days), and 6 months (180 days) as they are usually used for a prolonged period of time. All elements were incubated at a constant temperature of $36.6^{\circ} \mathrm{C}$ in a thermostatic chamber (Pol-Eko, Poland). After the incubation, saliva was collected and subjected to analytical procedures of multielemental analysis following 10-fold dilution. The procedural blanks, consisting of artificial saliva, were prepared in the same way as the other samples without contact with the specimens. Five independent experimental repetitions were performed.

\section{Trace Element Analysis}

The concentration of 23 elements (As, $\mathrm{Ba}, \mathrm{Cd}, \mathrm{Co}, \mathrm{Cr}, \mathrm{Cu}, \mathrm{Fe}$, Ge, Li, Mn, Mg, Mo, Ni, Pb, Rb, Tl, Ti, Sb, Sr, Sn, Zn, U, and $\mathrm{V})$ in artificial saliva following the incubation with ligatures was determined using an Elan DRC II ICP-QMS (PerkinElmerSCIEX, Ontario, Canada). Samples were introduced to plasma with the use of a cyclonic spray chamber, a concentric glass nebulizer and a quartz torch and injector and Pt cones. Argon was used as a nebulizer, auxiliary, and plasma gas (Linde Gas, Poland). The operating conditions for the ICP-MS were optimized on a daily basis and were as follows: RF power was 1050-1150 W; plasma gas flow rate was $16 \mathrm{~L} /$ min; nebulizer gas flow rates were $0.89-0.92 \mathrm{~L} / \mathrm{min}$, and auxiliary gas flow rate was $1.2 \mathrm{~L} / \mathrm{min}$; lens voltage was $7.00-8.5$ V. DRC mode was used in order to eliminate spectral interferences. ${ }^{52} \mathrm{Cr}$ and ${ }^{57} \mathrm{Fe}$ were analyzed in DRC mode with ammonia. A calibration was performed using a multielement stock solution (Multielement Calibration Standard 3, Atomic Spectroscopy Standard, PerkinElmer Pure; Certipur, Merck) containing the analyzed elements at a concentration of $10 \mathrm{mg} /$ $\mathrm{L}$ and single element $1000 \mathrm{mg} / \mathrm{L} \mathrm{Sn}$ solution (Certipur, Merck). A calibration based on a weighed least squares calibration curve was employed for all elements. Analyses were performed using internal standards (ICP Standard CertiPUR, Merck, Germany) to eliminate drift of the instrument and nonspectral interferences. Elements with $\mathrm{m} / \mathrm{z}$ values that overlap with $\mathrm{m} / \mathrm{z}$ polyatomic interferents from Ar and matrix components were analyzed in DRC mode. Argon with a purity of 99.999\% was used as a nebulizer, auxiliary, and plasma gas for the ICP-MS system (Linde Gas, Poland). High purity ammonia and oxygen were used as DRC reaction gases (Linde Gas, Poland).

For validation of the analytical data applied analytical procedure, two CRMs were used: SLRS-6-river water (NRC, Canada); TM-28.4-fortified lake water (National Water
Research Institute, Canada) and by using the analysis of spiked samples. After calibration and also during the analysis, all measurements were controlled by analysis of CRMs. The calibration curves for determined elements were linear in the range of calibration standards. The determination coefficient $R$ exceeded a value of 0.999 . The details on validation, accuracy and detection limits were previously provided [36]. The limits of detection (LOD) for the determined elements were counted according to LOD $=3.3 S / b$, where $S$ means the standard deviation of the result obtained for the blank samples and $b$ is the sensitivity $(n=5)$.

\section{Statistical Analyses and Calculations}

Statistical analyses were performed with Statistica 13.0 (StatSoft, USA). Because the data did not meet the assumption of Gaussian distribution (Shapiro-Wilk test, $p>0.05$ ), nonparametric methods were applied. The Kruskal-Wallis ANOVA with Dunn's post hoc test was applied to compare levels of elements released from different elastic ligatures and to compare levels during the different periods of incubation of stainless steel ligatures. The levels of metal release from elastomeric and stainless steel ligatures were compared with the Mann-Whitney $U$ test. A $p$ value $<0.05$ was considered as statistically significant.

To assess human health risks arising from the release of metals from the investigated ligatures, the determined concentrations were confronted with safety intake limits established by the European Food Safety Authority (EFSA) assuming the use of ligatures by $70-\mathrm{kg}$ adults and $30-\mathrm{kg}$ children. These limits are reinforced in European Union although they were established upon the evidence from toxicological studies and as such can serve as a reference point for general estimation of level of exposure to certain elements. Levels of $\mathrm{Cd}, \mathrm{Cr}$, and $\mathrm{Ni}$ were related to tolerable weekly intake (TWI) set at 2.5, 2.1, and $19.5 \mu \mathrm{g} / \mathrm{kg}$ body weight (bw), respectively [37-39], which in a 70-kg adult and 30-kg children would respectively amount to 175 and $75 \mu \mathrm{g} \mathrm{Cd}, 147$ and $63 \mu \mathrm{g} \mathrm{Cr}$, and 1365 and $585 \mu \mathrm{g} \mathrm{Ni}$. The determined concentration of Mn was related to adequate intake per day as established by the EFSA at a level of 3.0 for adults and $1.5 \mathrm{mg}$ for 10 -year-old children [40]. In the case of $\mathrm{Fe}$, the value of the population reference intake set at $11 \mathrm{mg}$ daily was assumed [40]. The determined levels of Co were compared with the health-based guideline level (GL) for chronic exposure for threshold related toxic effects established at a level of $1.6 \mu \mathrm{g} / \mathrm{kg}$ bw per day (equivalent of 112 and $48 \mu \mathrm{g}$ in a $70-\mathrm{kg}$ adult and $30-\mathrm{kg}$ children, respectively) [41]. For Sn, the PTWI set by the Joint FAO/WHO Expert Committee on Food Additives at a level of $14 \mathrm{mg} / \mathrm{kg}$ bw [42] as no regulatory assessment was provided by EFSA. These limits were used in calculation of total safe intake of each element in a period of 30,60 , and 90 days. 


\section{Results}

Incubation of elastomeric ligatures in artificial saliva for 1 month resulted in the release of $\mathrm{Cd}, \mathrm{Co}, \mathrm{Cr}, \mathrm{Mn}, \mathrm{Ni}$, and $\mathrm{Sn}$ at a total mean $\pm \mathrm{SD}$ released level of $0.31 \pm 0.09,0.98 \pm 0.30$, $3.96 \pm 1.31,14.7 \pm 8.5,13.8 \pm 4.8$, and $49.5 \pm 27.7 \mu \mathrm{g}$, respectively. No migration of $\mathrm{As}, \mathrm{Ba}, \mathrm{Cu}, \mathrm{Fe}, \mathrm{Ge}, \mathrm{Pb}, \mathrm{Sb}$, $\mathrm{Sc}, \mathrm{Tl}$, and $\mathrm{Zn}$ to artificial saliva was observed; the concentrations of these metals were below detection limits. The released levels of metals revealed some differences depending on ligature color (Fig. 2). The highest concentrations of $\mathrm{Cd}$ were observed in the case of the burgundy model, $\mathrm{Cd}$, in the case of orange and yellow; $\mathrm{Co}$ and $\mathrm{Ni}$, in the case of purple and burgundy; Mn, in the case of white and burgundy; and Sn, in the case of the purple model.

The stainless steel ligature released detectable concentrations of $\mathrm{Co}, \mathrm{Cr}, \mathrm{Fe}, \mathrm{Ni}$, and $\mathrm{Sn}$ after 1, 3, and 6 months of incubation. Other elements were always below detection limits. The level of released elements increased over the incubation time with the highest concentrations of $\mathrm{Co}, \mathrm{Cr}, \mathrm{Fe}, \mathrm{Ni}$, $\mathrm{Mn}$, and Sn observed after 6 months (Fig. 3). Their total mean $\pm \mathrm{SD}$ released level at this interval amounted to $28.6 \pm 0.2$, $21.7 \pm 0.2,623.5 \pm 3.0,1152.7 \pm 1.8,5.5 \pm 0.3$, and $22.6 \pm 0.2$ $\mu \mathrm{g}$, respectively. Compared to contents released from elastic ligatures during 1 month, the stainless steel appliances over the same time interval released 2.5-fold and 6.7-fold higher levels of $\mathrm{Ni}$ and $\mathrm{Co}$, respectively ( $p<0.05$ in both cases; Mann-Whitney $U$ test), and 9.7-fold, 5.5-fold, and 19.7-fold lower contents of $\mathrm{Cr}, \mathrm{Mn}$, and $\mathrm{Sn}$, respectively $(p<0.05$ in all cases; Mann-Whitney $U$ test).
As shown in Table 1, levels of metals released by elastic ligatures during 1 month of incubation were all much below safety limits for adults and children. In the case of stainless steel ligatures, an increase in the contribution to exposure was noted over the experimental period, particularly for $\mathrm{Cr}$ and $\mathrm{Ni}$. However, only in the case of the latter element did this contribution exceed 5 and $10 \%$ of the safety limit for adults and children, respectively (Table 1).

\section{Discussion}

The present study demonstrates that the release of trace elements can occur not only from stainless steel orthodontic appliances as previously demonstrated [20-24, 43-46] but also from elastic ligatures. This is most likely due to the chemical degradation of elastomeric elements under wet conditions [47, 48]. However, this phenomenon is limited only to selected metals since the concentration of the majority of the studied elements in artificial saliva incubated with the investigated ligatures were below detection limits. Contrary to stainless steel ligatures, which are sometimes used for a prolonged time, elastic ligatures are recommended to be replaced at every appointment because of force decay and deformation [47, 48]. Therefore, even though the former released lower contents of $\mathrm{Cr}, \mathrm{Mn}$, and Sn during the first month, this cannot be considered advantageous. Although differently colored elastic ligatures released varying concentrations of elements, these levels were always low, much below safety guideline values and constituted no threat to the health of adults or children. The
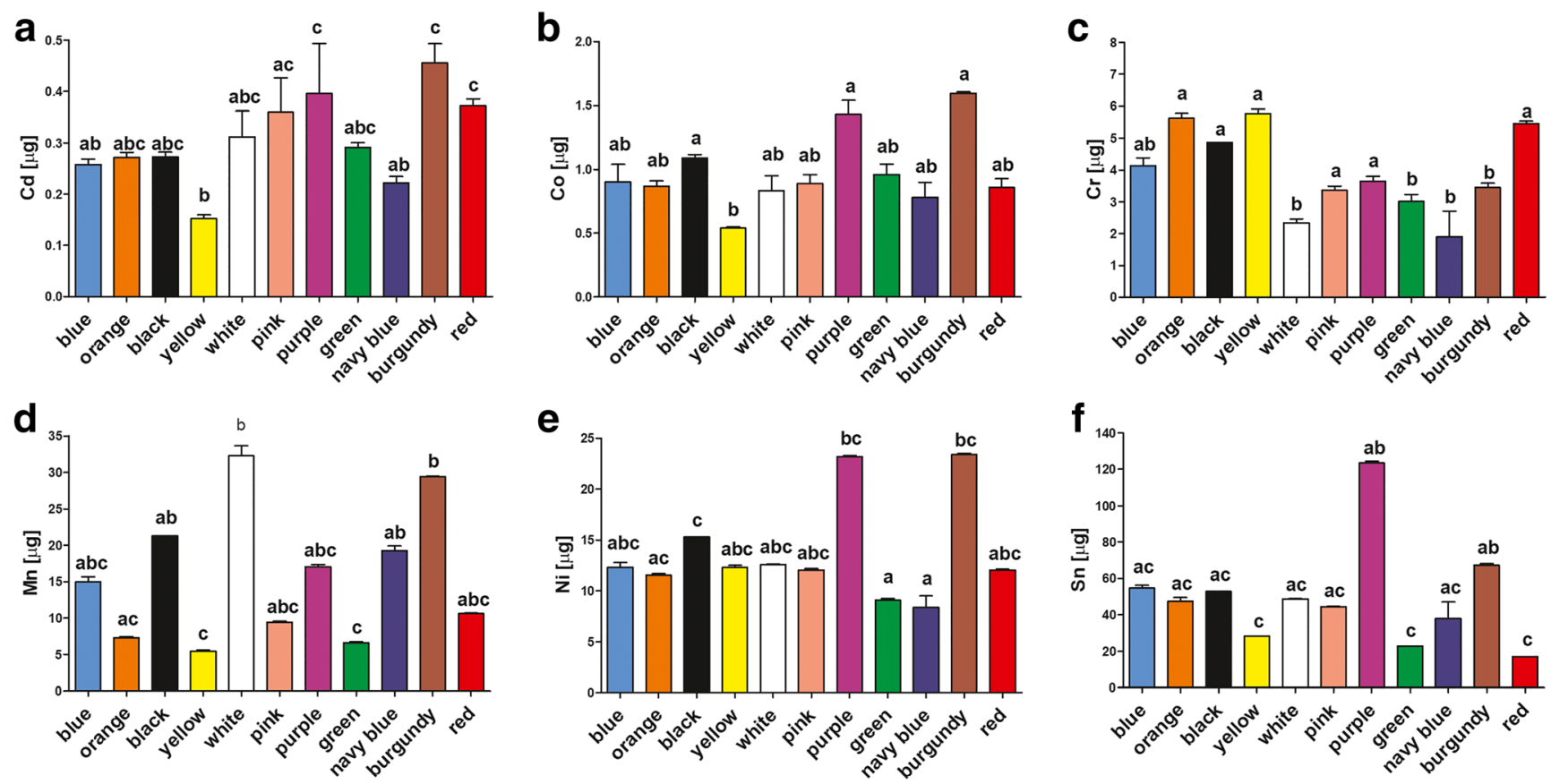

Fig. 2 The content (mean $\pm \mathrm{SD}$ ) of metals released from elastic ligatures during 1 month of incubation in artificial saliva. Different superscripts given above columns denote a significant difference between ligatures according to Dunn's post hoc test (Kruskal-Wallis ANOVA) 
Fig 3 The content (mean \pm SD) of metals released from stainless ligatures during 1,3 , and 6 months of incubation in artificial saliva. Different superscripts given above columns denote a significant difference in released elements between the investigated intervals according to Dunn's post-hoc test (Kruskal-Wallis ANOVA)

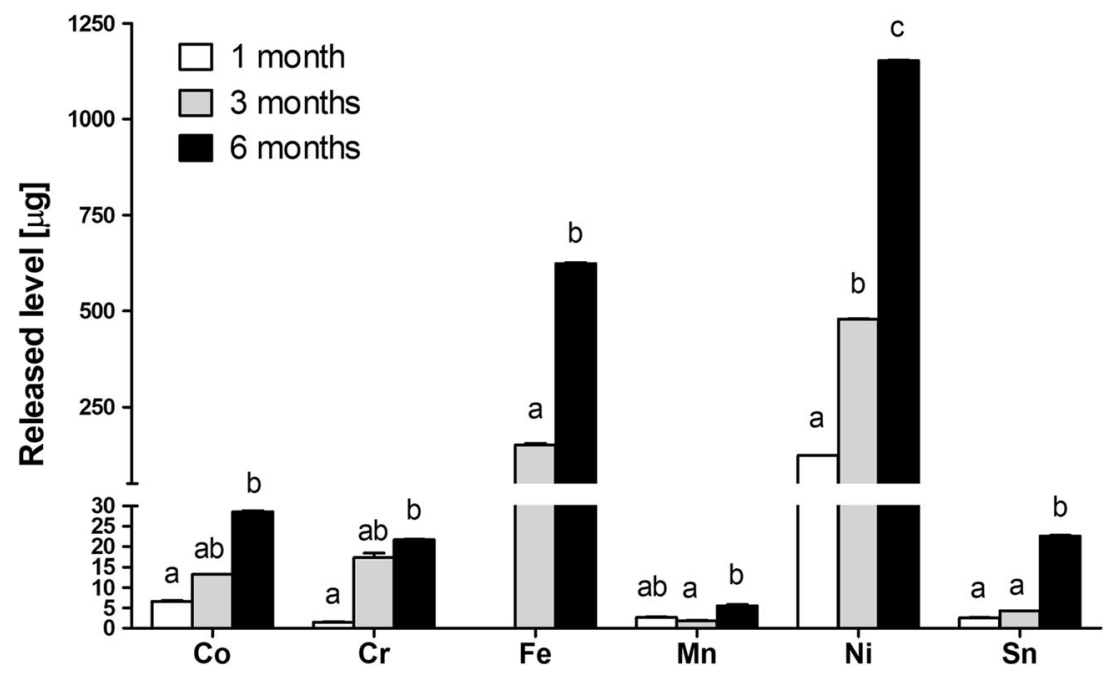

present study supports the decision to replace these appliances on a monthly basis not only due to potential changes in their physical properties but also to avoid any relevant exposure of patients to metallic elements during the treatment process. In contrast, the release of metals from stainless steel ligature was demonstrated to increase over the incubation period, and as demonstrated, a relevant content of Ni migrated to saliva during the 6-month period.

As demonstrated, there was no detectable release of As, Ba, $\mathrm{Cu}, \mathrm{Ge}, \mathrm{Pb}, \mathrm{Sb}, \mathrm{Sc}, \mathrm{Tl}$, and $\mathrm{Zn}$ from any studied ligature. From the group of investigated elements, stainless steel appliances

Table 1 Levels of metals released from elastic and stainless steel ligatures in relation to safety limits

\begin{tabular}{|c|c|c|c|c|c|}
\hline \multicolumn{2}{|c|}{ Element } & \multirow{3}{*}{$\begin{array}{l}\text { Elastic ligatures } \\
1 \text { month } \\
\% \text { of safety measure }\end{array}$} & \multicolumn{3}{|c|}{ Stainless steel ligatures } \\
\hline & & & 1 month & 3 months & 6 months \\
\hline & & & $\mathrm{e}^{*}$ for $70-\mathrm{k}$ & adult/for 30 & g children \\
\hline \multirow[t]{2}{*}{ Co } & Mean & $0.03 / 0.07$ & $0.2 / 0.5$ & $0.1 / 0.3$ & $0.2 / 0.4$ \\
\hline & Max & $0.05 / 0.12$ & $0.2 / 0.5$ & $0.1 / 0.3$ & $0.2 / 0.4$ \\
\hline \multirow[t]{2}{*}{$\mathrm{Cd}$} & Mean & $0.04 / 0.01$ & n.d. & n.d. & n.d. \\
\hline & Max & $0.07 / 0.18$ & n.d. & n.d. & n.d. \\
\hline \multirow[t]{2}{*}{$\mathrm{Cr}$} & Mean & $0.7 / 1.6$ & $0.3 / 0.6$ & $0.7 / 1.6$ & $0.9 / 2.0$ \\
\hline & Max & $1.0 / 2.4$ & $0.3 / 0.7$ & $0.7 / 1.7$ & $0.9 / 2.0$ \\
\hline \multirow[t]{2}{*}{$\mathrm{Fe}$} & Mean & n.d & n.d & 0.01 & 0.04 \\
\hline & Max & n.d. & n.d. & 0.02 & 0.04 \\
\hline \multirow[t]{2}{*}{$\mathrm{Ni}$} & Mean & $0.25 / 0.59$ & $2.3 / 5.2$ & $2.9 / 6.8$ & $5.0 / 11.5$ \\
\hline & Max & $0.43 / 1.0$ & $2.4 / 5.3$ & $3.0 / 6.9$ & $5.1 / 11.6$ \\
\hline \multirow[t]{2}{*}{$\mathrm{Mn}$} & Mean & $0.01 / 0.03$ & $<0.01$ & $<0.01$ & $<0.01$ \\
\hline & Max & $0.03 / 0.07$ & $<0.01$ & $<0.01$ & $<0.01$ \\
\hline \multirow[t]{2}{*}{$\mathrm{Sn}$} & Mean & $<0.01$ & $<0.01$ & $<0.01$ & $<0.01$ \\
\hline & Max & $<0.01$ & $<0.01$ & $<0.01$ & $<0.01$ \\
\hline
\end{tabular}

* Safety measures used for calculations of total safe intake during 1,3, and 6 months are explained for each metal in "Material and Methods"

n.d. element not detected released only $\mathrm{Co}, \mathrm{Cr}, \mathrm{Fe}, \mathrm{Mn}, \mathrm{Ni}$, and $\mathrm{Sn}$. As previously shown by Mikulewicz et al., the orthodontic appliance consisting of stainless steel wires, bands, brackets, and ligatures may also leach metals such as $\mathrm{Mg}, \mathrm{Ti}, \mathrm{V}, \mathrm{Cu}$, and $\mathrm{Zn}$ [21]. Contrary to stainless steel ligatures, their elastomeric counterparts released $\mathrm{Cd}$ to artificial saliva. The safety of stainless steel appliances used in orthodontic treatment in this regard has also been confirmed previously [21] and provides a potential advantage of such ligatures compared to the elastomeric ones. The exact source of $\mathrm{Cd}$ in elastomeric appliances remains unknown although if one considers the variation of its levels observed between models differing in color, the contribution of dyes used in their production may be hypothesized. The identification of all sources of $\mathrm{Cd}$ exposure in humans is of high importance as it can cause systemic organ toxicity and its compounds have been classified as carcinogenic by International Research on Cancer [49]. However, the detected levels in the present study were in magnitudes irrelevant for risk assessment and constitute no threat to human health.

Previously conducted investigations have reported that orthodontic appliances made of stainless steel may release levels of Ni that may pose a risk to human health [20, 21, 50]. The present study confirms these observations and further adds that the Ni content migrating to saliva may increase over the course of ligature use. As observed, patients treated with a self-ligating bracket system made of stainless steel have revealed increased salivary $\mathrm{Ni}$ concentrations [51]. This is an important finding since these appliances are fixed in the oral cavity for a prolonged time, often even longer than the studied period. As found, a pool released during 6 months of incubation would constitute 5.0 and $11.5 \%$ of tolerable intake for a $70-\mathrm{kg}$ adult and $30-\mathrm{kg}$ children, respectively. These results highlight that the prolonged use of orthodontic stainless steel ligatures may represent a relevant source of Ni intake, particularly important in view of the fact that some individuals can develop a cutaneous reaction after oral $\mathrm{Ni}$ intake known as 
systemic contact dermatitis (SCD) [52]. Cases of SCD following the use of stainless steel orthodontic appliances have been documented [53-55]. Apart from SCD, chronic oral exposure to Ni can lead to other adverse effects, e.g., hematotoxicity and nephrotoxicity [56]. One should, however, note that there are other more relevant sources of oral $\mathrm{Ni}$ in the general population, such as selected food supplements or cultivated mushrooms [57-59]. Nevertheless, considering that the content of $\mathrm{Ni}$ in selected foodstuffs and subsequent dietary exposures to $\mathrm{Ni}$ from food consumption are already of increasing concern [38], an effort should be undertaken to minimize the contribution of additional sources of exposure to this metal. All in all, these observations highlight the advantages of elastic ligatures from which only fractional amounts of $\mathrm{Ni}$, with no relevant contribution to human exposure, were released over the course of 1 month (a typical period of their use).

Other elements which can cause SCD include $\mathrm{Cr}$, Co, and $\mathrm{Zn}[60,61]$. The release of the latter from dental fillings was shown to be implicated the oral lichen planus, palmoplantar pustulosis, and maculopapular rash [62-64]. No migration of $\mathrm{Zn}$ from stainless steel or elastic ligatures was observed in the present study and highlights that these appliances are safe in this regard. One should however note that previous studies have shown that $\mathrm{Zn}$ may be released from other stainless steel components of orthodontic appliance (wires, bands, or brackets) [21]. Levels of released $\mathrm{Cr}$ and Co from both types of tested ligatures were also too low to constitute any risk for human health in both adults and children, even if prolonged treatment with the stainless steel type would be assumed. This is particularly reassuring if one considers that the composition of the alloy of the stainless steel was composed of $17-20 \%$ of Cr. One should also note that the toxicity of Cr strongly depends on its chemical speciation with a hexavalent form considered as a human carcinogen contrary to trivalent compounds which are known to be much less toxic [65]. Stainless steel alloys have in turn been demonstrated to release only the latter forms unless under specific conditions (highly oxidative and alkaline), not present in the oral cavity, are chronically applied [66, 67].

Contrary to stainless steel appliances, none of the investigated elastic ligatures released detectable amounts of Fe. Although the migration from the former increased over the incubation period, the determined concentrations were low and their comparison with the population reference intake indicates that there is no relevant risk of Fe exposure via the use of the appliances in both adults and children. The release of $\mathrm{Mn}$ and $\mathrm{Sn}$ from elastic and stainless steel ligatures also occurred at a very low level. On comparison with the guideline values, one can conclude that the investigated appliances do not constitute any relevant source of human exposure to these metals. One should also note that $\mathrm{Sn}$ is mostly toxic in organic forms, while such compounds are not employed in the production of the orthodontic appliances [68]. Interestingly, the investigated elastic ligatures revealed some variation in the released metals depending on their color. These differences are likely due to the chemical composition of the pigments used during the manufacturing process in order to meet the demands of younger patients, and to prevent color loss during food consumption [69]. In the present study, the most pronounced differences were observed in the case of Sn with a purple ligature releasing at least 2-fold higher levels than other elastic ligatures - this may be due to the use of inorganic Sn (particularly $\mathrm{Sn}(\mathrm{II})$ chloride) in purple pigment production [70].

Although the present study provides a general overview on the release of metals from ligatures under mimicked intraoral conditions, one should note that the experiments were conducted under static conditions and that this introduces a study limitation. In the oral cavity, the ligatures are not only exposed to saliva but also to significant and rapid changes in various physicochemical parameters such as $\mathrm{pH}$ and temperature, mechanical forces during food consumption, as well as microbial activities that depend on oral hygiene status. All of these can contribute to deformation and degradation of ligatures [69, 71-73] resulting in potentially increased levels of released metals. Moreover, the composition of artificial saliva did not include enzymes which activity may also be relevant for metal release. Therefore, further prospective in vivo studies that would consider the abovementioned parameters are necessary for a full assessment of this phenomenon. One should also note that the subject of this study was a release of metals from orthodontic ligatures not a release from complete dental appliances that also include brackets, arch-wires, retainer alignment, and wire, all of which can be prepared from a variety of materials that may also potentially contribute to metal release. Thus, the use of elastic ligatures instead of stainless steel ligatures may also represent a strategy to decrease to metal exposure in orthodontic patients.

\section{Conclusions}

This study provides an insight into the release of metals and metalloids from orthodontic elastomeric and stainless steel ligatures which are increasingly used in the general population. From the 23 investigated elements, only Co, $\mathrm{Cd}, \mathrm{Cr}, \mathrm{Ni}, \mathrm{Mn}$, and $\mathrm{Sn}$ migrated from elastic ligatures to artificial saliva but the observed levels were always much below safety limits. In turn, stainless steel ligatures released $\mathrm{Co}, \mathrm{Cr}, \mathrm{Fe}, \mathrm{Ni}$, and $\mathrm{Sn}$ from which only the level of $\mathrm{Ni}$ was of concern given the fact that these appliances are used over a prolonged period, not only in adults but also in children. The present study affirms the safety of ligatures in orthodontic treatment, although tending to support the use of elastic ligatures replaced on a monthly basis over the prolonged use of stainless steel counterparts. 


\section{Compliance with ethical standards}

Conflict of Interest The authors declare that they have no conflict of interest.

Open Access This article is distributed under the terms of the Creative Commons Attribution 4.0 International License (http:// creativecommons.org/licenses/by/4.0/), which permits unrestricted use, distribution, and reproduction in any medium, provided you give appropriate credit to the original author(s) and the source, provide a link to the Creative Commons license, and indicate if changes were made.

\section{References}

1. Iavicoli I, Falcone G, Alessandrelli M, Cresti R, De Santis V, Salvatori S, Alimonti A, Carelli G (2006) The release of metals from metal-on-metal surface arthroplasty of the hip. J Trace Elem Med Biol 20:25-31

2. Keegan GM, Learmonth ID, Case CP (2007) Orthopaedic metals and their poten - tial toxicity in the arthroplasty patient. A review of current knowledge and future strategies. J Bone Joint Surg 89:567573

3. Gao X, He RX, Yan SG, Wu LD (2011) Dermatitis associated with chromium following total knee arthroplasty. J Arthroplast 26:665

4. Prasad K, Bazaka O, Chua M, Rochford M, Fedrick L, Spoor J, Symes R, Tieppo M, Collins C, Cao A et al (2017) Metallic biomaterials: current challenges and opportunities. Materials 10:884

5. Bjørklund G, Lindh U, Aaseth J, Mutter J, Chirumbolo S (2019) Mercury in dental amalgams: a great concern for clinical toxicology in developing countries? J Trace Elem Med Biol 51:9-11

6. Appukuttan DP (2016) Strategies to manage patients with dental anxiety and dental phobia: literature review. Clin Cosmet Investig Dent 8:35-50

7. Hafez HS, Selim EMN, Eid FHK, Tawfik WA, Al-Ashkar EA, Mostafa YA (2011) Cytotoxicity, genotoxicity, and metal release in patients with fixed orthodontic appliances: a longitudinal invivo study. Am J Orthod Dentofac Orthop 140:298-308

8. Maylani B, Berzins DW (2007) Effect of disinfecting solutions on the mechanical properties of orthodontic elastomeric ligatures. Angle Orthod 77:681-687

9. Eliades T, Eliades G (2005) In vitro degradation of polyurethane orthodontic elastomeric modules. J Oral Rehab 32:72-77

10. Casaccia GR, Gomes JC (2007) Microbiological evaluation of elastomeric chains. Angle Orthod 77:890-893

11. Branco Losito KA, Simoni Lucato A (2014) Force decay in orthodontic elastomeric chains after immersion in disinfection solutions. Braz J Oral Sci 13-14

12. Walton DK, Fields HW, Johnston WM, Rosenstiel SF, Firestone AR, Christensen JC (2010) Orthodontic appliance preferences of children and adolescents. Am J Orthod Dentofac Orthop 138:698689

13. Ardeshna AP, Vaidyanathan TK (2009) Colour changes of orthodontic elastomeric module materials exposed to in vitro dietary media. J Orthod 36:177-185

14. Buchmann N, Senn C, Ball J, Brauchli L (2012) Influence of initial strain on the force decay of currently available elastic chains over time. Angle Orthod 82:529-535

15. Masoud AI, Bulic M, Viana G, Bedran-Russo AK (2016) Force decay and dimensional changes of thermoplastic and novel thermoset elastomeric ligatures. Angle Orthod 86:818-825
16. Kovatch JS, Lautenschlager EP, Apfel DA Keller JC (1976) Loadextension-time behavior of orthodontic elastics. J Dent Res 55:783786

17. Dowling PA, Jones WB, Lagerstrom L, Sandham JA (1998) An investigation into the behavioural characteristics of orthodontic elastomeric modules. Br J Orthod 25:197-202

18. Lam TV, Freer TJ, Brockhurst PJ, Podlich HM (2002) Strength decay of orthodontic elastomeric ligatures. J Orthod 29:37-43

19. Khambay B, Millett D, McHugh S (2005) Archwire seating forces produced by different ligation methods and their effect on frictional resistance. Eur J Orthod 27:302-308

20. Mikulewicz M, Chojnacka K (2010) Trace metal release from orthodontic appliances by in vitro studies: a systematic literature review. Biol Trace Elem Res 139:241-256

21. Mikulewicz M, Chojnacka K, Woźniak B, Downarowicz P (2012) Release of metal ions from orthodontic appliances: an in vitro study. Biol Trace Elem Res 146:272-280

22. Mikulewicz M, Chojnacka K, Wołowiec P (2014) Release of metal ions from fixed orthodontic appliance: an in vitro study in continuous flow system. Angle Orthod 84(1):140-148

23. Wendl B, Wiltsche H, Lankmayr E, Winsauer H, Walter A, Muchitsch A (2017) Metal release profiles of orthodontic bands, brackets, and wires: an in vitro study. J Orofac Orthop 78:494-503

24. Tahmasbi S, Sheikh T, Hemmati YB (2017) Ion release and galvanic corrosion of different orthodontic brackets and wires in artificial saliva. J Contemp Dent Pract 18:222-227

25. Mikulewicz M, Chojnacka K (2010) Trace metal release from orthodontic appliances by in vivo studies: a systematic literature review. Biol Trace Elem Res 137:127-138

26. Ağaoğlu G, Arun T, Izgi B, Yarat A (2001) Nickel and chromium levels in the saliva and serum of patients with fixed orthodontic appliances. Angle Orthod 71(5):375-379

27. Moghadam MG, Hoshyar R, Mikulewicz M, Chojnacka K, Bjørklund G, Pen JJ, Azadi NA, Pirsaheb M, Dashtaki M, Mansouri B (2019) Biomonitorization of metal ions in the serum of Iranian patients treated with fixed orthodontic appliances in comparison with controls in eastern Iran. Environ Sci Pollut Res. https://doi.org/10.1007/s11356-019-06414-1

28. Pereira ML, Silva A, Tracana R, Carvalho GS (1994) Toxic effects caused by stainless steel corrosion products on mouse seminiferous cells. Cytobios 77:73-80

29. Bass JK, Fine H, Cisneros GJ (1993) Nickel hypersensitivity in the orthodontic patient. Am J Orthod Dentofac Orthop 103:280-285

30. Hanson M, Lobner D (2004) In vitro neuronal cytotoxity of latex and nonlatex orthodontic elastics. Am J Orthod Dentofac Orthop 126:65

31. Santos RL, Pithon MM, Martins FO, Romanos MTV, Ruellas ACO (2010) Cytotoxicity of latex and non-latex orthodontic elastomeric ligatures on L929 mouse fibroblasts. Braz Dent J 21:205-210

32. Järup L (2003) Hazards of heavy metals contamination. Br Med Bull 68(1):167-182

33. Mamtani R, Stern P, Dawood I, Cheema S (2011) Metals and disease: a global primary health care perspective. J Toxicol 2011:1-11

34. Rzymski P, Tomczyk K, Rzymski P, Poniedziałek B, Opala T, Wilczak M (2015) Impact of heavy metals on the female reproductive system. Ann Agric Environ Med 22(2):259-264

35. Elekdak-Turk S, Ozkalayci N, Isci D, Turk T (2010) Color preferences of patients receiving elastic ligatures. Eur J Dent 4:171-174

36. Markiewicz B, Sajnóg A, Lorenc W, Hanć A, Komorowicz I, Suliburska J, Kocyłowski R, Barałkiewicz D (2017) Multielemental analysis of 18 essential and toxic elements in amniotic fluid samples by ICP-MS: full procedure validation and estimation of measurement uncertainty. Talanta 174:122-130

37. EFSA (2011) Statement on tolerable weekly intake for cadmium. EFSA J 9:1975 
38. EFSA (2015) Scientific opinion on the risks to public health related to the presence of nickel in food and drinking water. EFSA J 13: 4002

39. EFSA (2014) Scientific Opinion on the risks to public health related to the presence of chromium in food and drinking water. EFSA J 12: 3595

40. EFSA (2017) Dietary reference values for nutrients. Summary report. EFSA supporting publication. EFSA J 14:e15121E

41. EFSA (2012) Scientific Opinion on safety and efficacy of cobalt compounds (E3) as feed additives for all animal species: Cobaltous acetate tetrahydrate, basic cobaltous carbonate monohydrate and cobaltous sulphate heptahydrate, based on a dossier submitted by TREAC EEIG1. EFSA J 10:1-27

42. JEFCA (2006) Evaluation of certain food contaminants. Sixtyfourth report of the Joint FAO/WHO Expert Committee on Food Additives. World Health Organization, Geneva

43. Faccioni F, Franceschetti P, Cerpelloni M, Fracasso ME (2003) In vivo study on metal release from fixed orthodontic appliances and DNA damage in oral mucosa cells. Am J Orthod Dentofac Orthop 124:687-693

44. Amini F, Borzabadi Farahani A, Jafari A, Rabbani M (2008) In vivo study of metal content of oral mucosa cells in patients with and without fixed orthodontic appliances. Orthod Craniofacial Res 11: 51-56

45. Ortiz AJ, Fernandez E, Vicente A, Calvo JL, Ortiz C (2011) Metallic ions released from stain-less steel, nickel-free, and titanium orthodontic alloys: toxicity and DNA damage. Am J Orthod Dentofac Orthop 140:115-122

46. Eliades T, Pratsinis H, Kletsas D, Eliades G, Makou M (2004) Characterization and cytotoxicity of ions released from stainless steel and nickel-titanium orthodontic alloys. Am J Orthod Dentofac Orthop 125:24-29

47. Taloumis LJ, Smith TM, Hondrum SO, Lorton L (1997) Force decay and deformation of orthodontic elastomeric ligatures. Am J Orthod Dentofac Orthop 111:1-11

48. Petersen A, Rosenstein S, Kim KB, Israel H (2009) Force decay of elastomeric ligatures: influence on unloading force compared to self-ligation. Angle Orthod 79:934-938

49. Rafati Rahimzadeh M, Rafati Rahimzadeh M, Kazemi S, Moghadamnia AA (2017) Cadmium toxicity and treatment: an update. Caspian J Intern Med 8:135-145

50. Jensen CS, Lisby S, Baadsgaard O, Byrialsen K, Menné T (2003) Release of nickel ions from stainless steel alloys used in dental braces and their patch test reactivity in nickel-sensitive individuals. Contact Dermatitis 48(6):300-304

51. Gölz L, Knickenberg AC, Keilig L et al (2016) Nickel ion concentrations in the saliva of patients treated with self-ligating fixed appliances: a prospective cohort study. J Orofac Orthop 77:85-93

52. Fabbro SK, Zirwas MJ (2014) Systemic contact dermatitis to foods: nickel, BOP, and more. Curr Allergy Asthma Rep 14:463

53. Kerosuo H, Kanerva L (1997) Systemic contact dermatitis caused by nickel in a stainless steel orthodontic appliance. Contact Dermatitis 36:112-113

54. Rahilly G, Price N (2003) Nickel allergy and orthodontics. J Orthod 30:171-174

55. Ehrnrooth M, Kerosuo H (2009) Face and neck dermatitis from a stainless steel orthodontic appliance. Angle Orthod 79:1194-1196

56. Das KK, Das SN, Dhundasi SA (2008) Nickel, its adverse health effects and oxidative stress. Indian J Med Res 128:412-425
57. Mleczek M, Rzymski P, Budka A, Siwulski M, Jasińska A, Kalač P, Poniedziałek B, Gąsecka M, Niedzielski P (2018) Elemental characteristics of mushroom species cultivated in China and Poland. $\mathrm{J}$ Food Compos Anal 66:168-178

58. Poniedziałek B, Niedzielski P, Kozak L, Rzymski P, Wachelka M, Rzymska I, Karczewski J, Rzymski P (2018) Monitoring of essential and toxic elements in multi-ingredient food supplements produced in European Union. J Consum Prot Food Saf 13:41-48

59. Rzymski P, Budzulak J, Niedzielski P, Klimaszyk P, Proch J, Kozak L, Poniedziałek B (2018) Essential and toxic elements in commercial microalgal food supplements. J Appl Phycol. https://doi.org/10. 1007/s10811-018-1681-1

60. Yoshihisa Y, Shimizu T (2012) Metal allergy and systemic contact dermatitis: an overview. Dermatol Res Pract 2012:749561

61. Summer B, Fink U, Zeller R, Rueff F, Maier S, Roider G (2007) Patch test reactivity to a cobalt-chromium-molybdenum alloy and stainless steel in metal-allergic patients in correlation to the metal ion release. Contact Dermatitis 57:353-359

62. Ido T, Kumakiri M, Kiyohara T, Sawai T, Hasegawa Y (2002) Oral lichen planus due to zinc in dental restorations. Contact Dermatitis 47:51

63. Shimizu T, Kobayashi S, Tanaka M (2003) Systemic contact dermatitis to zinc in dental fillings. Clin Exp Dermatol 28:675-676

64. Yanagi T, Shimizu T, Abe R, Shimizu H (2005) Zinc dental fillings and palmoplantar pustulosis. Lancet 366:1050

65. Sun H, Brocato J, Costa M (2015) Oral chromium exposure and toxicity. Curr Environ Health Rep 2:295-303

66. Midander K, de Frutos A, Hedberg Y, Darrie G, Odnevall Wallinder I (2010) Bioaccessibility studies of ferro-chromium alloy particles for a simulated inhalation scenario: a comparative study with the pure metals and stainless steel. Integr Environ Assess Manag 6: $441-455$

67. Hedberg Y, Odnevall Wallinder I (2013) Metal release and speciation of released chromium from a biomedical CoCrMo alloy into simulated physiologically relevant solutions. J Biomed Mater Res B Appl Biomater 102:693-699

68. Barbosa CML, Ferrão FM, Graceli JB (2018) Organotin compounds toxicity: focus on kidney. Front Endocrinol 9:256

69. Kawabata E, Dantas VL, Kato CB, Normando D (2016) Color changes of esthetic orthodontic ligatures evaluated by orthodontists and patients: a clinical study. Dental Press J Orthod 21:53-67

70. Brackenbury KFG, Jones L, Nel I, Koch KR, Wyrley-Birch JM (1987) Tin (II) chloride in the analytical chemistry of the platinum metals: From the "purple of cassius" to polyurethane foams. Polyhedron 6:71-78

71. Condo R, Casaglia A, Armellin E et al (2013) Traditional elastic ligatures versus slide ligation system. A morphological evaluation. Oral Implantol 6:15-24

72. Hwang CJ, Cha JY (2003) Mechanical and biological comparison of latex and silicone rubber bands. Am J Orthod Dentofacial Orthop 124:379-386

73. Nakhaei S, Habib RA, Agahi AA, Rezaeizadeh M (2017) Discoloration and force degradation of orthodontic elastomeric ligatures. Dental Press J Orthod 22:45-54

Publisher's Note Springer Nature remains neutral with regard to jurisdictional claims in published maps and institutional affiliations. 